\title{
ASPECTOS ÉTICOS NO USO DA INTERNET COMO FERRAMENTA DE PESQUISA
}

\section{ETHICAL ISSUES IN THE USE OF INTERNET AS A RESEARCH TOOL}

\author{
Lívia Letícia Zanier Gomes ${ }^{1}$ \\ Osvaldo Dalberio ${ }^{2}$
}

Resumo: O presente artigo discute a ética no uso da internet enquanto ferramenta de pesquisa científica, mostrando a distinção entre ética e moral e entre ética e o fazer comum. Para isso, busca as origens da internet para comparar a facilidade de acesso aos textos científicos nela presentes versus a dificuldade de acesso aos textos científicos impressos. Questiona, ainda, se a pressão advinda dos centros de pesquisa frente à quantidade de publicações acarreta uma postura antiética do cientista. Focaliza, sobretudo, a necessidade de se discutir a postura ética no espaço acadêmico para que o pesquisador seja produtor de textos originais e não plagiados da internet.

Palavras-chave: Ética. Internet. Texto científico.

Abstract: The following article discusses the ethical use of the internet as a scientific research tool by showing the difference between ethics and moral and between ethics and the common sense doing. For that, the text explores since the internet origins in order to compare the access facility to the scientific texts in the internet versus the access difficulty to the printed versions of scientific texts. It asks, also, if the pressure came from the research centers about the quantity of publications brings an anti-ethics attitude to the scientist. It focuses, specially, on the necessity of constructing a discussion about the ethical posture in the academic environment to make the researcher an original texts writer and not a writer of plagiarized internet texts.

Keywords: Ethic. Internet. Scientific text.

\footnotetext{
1 Especialista em Docência na Educação Superior pela Universidade Federal do Triângulo Mineiro UFTM (2008). Bacharel e Licenciada em Letras, Universidade de São Paulo - USP (2006). Professora efetiva do Instituto Federal do Triângulo Mineiro, campus Uberaba (MG). Membro do grupo de pesquisas Formação de Professor, na linha de pesquisa Formação ética do professor, vinculado à Universidade Federal do Triângulo Mineiro - UFTM, Uberaba, Brasil.

${ }^{2}$ Doutor em Serviço Social, Universidade Estadual Paulista "Júlio de Mesquita Filho" -UNESP (2008); Mestre em Educação, Universidade de Campinas - UNICAMP (1990); Especialista em ética e filosofia moral, Università degli Studio di Trieste, Itália (2008); Especialista em filosofia clínica pelo Instituto Packter de Filosofia Clinica de Porto Alegre, RS (2003); Especialista em avaliação pela Universidade de Brasília - UnB (2001). Filósofo, Pontifícia Universidade Católica de Campinas - PUCCAMP, (1986). Professor adjunto da Universidade Federal do Triângulo Mineiro - UFTM. Membro dos grupos de pesquisas: Prática de Pesquisa (PRAPES), vinculado a UNESP, campus de Franca e do grupo de pesquisa Formação de Professor, com a linha de pesquisa: formação ética do professor, vinculado à Universidade Federal do Triângulo Mineiro - UFTM, Uberaba, Brasil.
} 
Disponibilizada mundialmente em 1991, a world wide web é hoje uma ferramenta ao alcance de grande parte da comunidade científica. Seja em sites de acesso aberto ou de acesso restrito, muito se deve à internet no meio científico atual, pois nela se pesquisam e se publicam informações e reflexões científicas novas a todo o momento. E é com a grande facilidade de acesso a tal teia de informações que muitas questões de cunho científico podem ser levantadas.

Destarte, o objetivo deste texto é estudar a relação entre ética e a internet enquanto ferramenta de pesquisa científica. Os questionamentos em torno dos quais giraram essas reflexões foram os seguintes: A internet pode ser considerada uma ferramenta de pesquisa de qualidade?; A internet é responsável pelo uso não ético de informações em pesquisas científicas?; A internet facilita o plágio de trabalhos acadêmicos?; A internet aumenta as chances de paráfrases não éticas de pesquisas de outrem?

Para embasar este estudo, retomamos as questões referentes ao surgimento da internet como ferramenta de pesquisa e apresentamos as questões teóricas e etimológicas que diferenciam ética de moral.

A Internet nasceu no período da Guerra Fria (fim dos anos cinquenta) com estudos realizados pela Agência de Pesquisas em Projetos Avançados (ARPA) composta por militares e pesquisadores estadunidenses. A finalidade da Advanced Research Projects Agency Network (ARPANet) era provar a superioridade estadunidense com relação à tecnologia da União Soviética frente ao lançamento do Sputinik (pimeiro satélite artificial do mundo). Além disso, por temerem um ataque nuclear, a agência funcionava para conectar centros universitários americanos de pesquisa para que a troca de informações fosse rápida e protegida e para fazer com que toda a informação de pesquisa daquele país estivesse, de algum modo, protegida contra ataques nucelares. Foi a evolução da ARPANet que culminou na atual internet.

Pouco tempo depois, nos anos 1970, o e-mail foi criando espaço entre os pesquisadores pelo fato de possibilitar uma troca rápida e eficaz de informações. $\mathrm{Na}$ década de 1990, com o lançamento do World Wide Web, houve um espetacular crescimento de usuários da internet no mundo. A partir de então, tornou-se possível, com poucas dificuldades de maquinarias, a troca e busca de informações, antes inacessíveis, a pessoas comuns, bem como a pesquisadores. 
De tal maneira, frente ao crescimento acelerado e tão positivo da troca de informações, vieram inúmeras preocupações e questões éticas relacionadas ao uso da internet. Hoje, tanto crimes quanto pesquisas de grande porte podem ter grandes contribuições advindas deste ciberespaço.

Se pensarmos num passado ainda bastante próximo, perceberemos que, com a propagação de material científico pela internet, o papel das editoras, antes responsáveis pela redistribuição do conhecimento que por elas passava, diminuiu consideravelmente e tem esta diminuição como tendência. Isso não significa o prenúncio do fim do uso dos impressos, mas mostra que o acesso à informação científica tem como tendência, tornar-se algo mais livre e acessível à comunidade científica.

Com a facilidade de acesso, criaram-se revistas científicas eletrônicas cujo aumento em número possibilita e exige o aumento quantitativo de publicações; o crescimento em número de publicações caminha juntamente com crescimento de qualidade acadêmica de tais publicações. A acessibilidade a inúmeros artigos facilita ao estudante acadêmico, pressionado pela exigência universitária e pela necessidade de se publicar resultados de pesquisa, fazer cópia de pequenos trechos de variados artigos. Isso possibilita a elaboração de textos sem originalidade e sem cunho científico e acadêmico do ponto de vista ético. Não é à toa que "[...] para o não reconhecimento da autoria, há o crime de plágio; para o não registro das fontes, há o crime de falsidade argumentativa" (DINIZ, 2008, p. 182).

Para falarmos da questão ética envolvida no processo de conhecimento científico online recorreremos a uma rápida distinção entre moral e ética.

O termo moral, do latim, mores, significa costume. O termo ético define-se como disciplina filosófica que tem por objeto de estudo os julgamentos de valor na medida em que estes se relacionam com a distinção entre o bem e o mal.

[...] enquanto a moral consiste no conjunto de prescrições que orienta a conduta de indivíduos e grupos nas sociedades, a ética se apresenta como um olhar crítico sobre a moral, perguntando pelos fundamentos dos valores que a sustentam. (RIOS, 2007, p. 49).

Assim, a moral possui um caráter prático e pode variar de sociedade para sociedade uma vez que se constitui no certo e no errado dos costumes vigentes. Diferentemente, a ética é uma reflexão filosófica que possui um caráter universalista e não relativista como a moral. Transpondo para o campo em discussão neste texto, 
pensemos no seguinte: a pressão por parte dos órgãos financiadores de pesquisas científicas é enorme para que seu "mercado" de publicações esteja sempre fomentado. Assim, publicações do tipo "colcha de retalho" em que se retiram trechos de artigo científico e trechos de outros não científicos juntando-os com a finalidade de se apresentar um "novo" texto tornam-se comuns.

Os incentivos para que as pessoas trapaceiem são grandes demais para
serem ignorados. Até que as pessoas sejam penalizadas ao invés de
recompensadas por publicar mais do que o humanamente possível sem
recorrer a duplicação, co-autorias periféricas sem nenhuma contribuição
significativa para o trabalho, plágio e ações fraudulentas em geral, a
recompensa por se safar, comparada à possibilidade de ser descoberto,
farão com que correr o risco seja uma opção muito atraente. Como a
maioria das condutas ilícitas em editoração tende a ser no sentido de
multiplicar o número de publicações (através de duplicação, plágio ou co-
autoria periférica) e somando-se o fato de que as revistas científicas são
amplamente complacentes em relação a isso, já que os interesses mútuos
coincidem, somente alterando drasticamente os incentivos para publicação
essa situação irá mudar. (GOLLOGLY \& MOMEN, 2006)

Questões assim estão se tornando costumeiras na academia. Fica óbvio, porém, que não se enquadrariam em princípios éticos como o respeito e a justiça. "A ética questiona a moral - as ações morais têm sua origem nos costumes de cada sociedade. Esses costumes estão fundados em valores - o que é costumeiro é confundido, muito frequentemente, com o que é bom." (RIOS, 2007, p. 49).

Assim, falamos, aqui, do aspecto ético na utilização da internet por procurarmos algo que seja válido universalmente assim como é universal o acesso científico pela World Wide Web. Pesquisar inúmeros textos científicos antes de se produzir um texto novo e verdadeiramente de autoria é algo válido. Porém, é preciso utilizar tais textos de maneira não plagiada, por exemplo. Um pesquisador pode ler vários artigos científicos a fim de encontrar, nos mesmos, questões ainda não solucionadas por outros para daí respondê-las. Pode, ainda, ler outros textos científicos com a intenção de perceber a linha de raciocínio já executada por outros autores e para procurar outros caminhos para resolver uma questão científica ainda em aberto. A leitura de pesquisas disponibilizadas no meio online deve fomentar a mente do pesquisador para que ele faça suas pesquisas e seus textos de maneira nova e inédita e não à maneira do "recorta e cola" ou a outras como as já apontadas por Gollogly \& Momen, maneiras essas que nada possuem de condizentes ao meio científico, mas as quais não podem ser mais descartadas dentre as práticas atuais.

É possível afirmarmos que a internet não é a principal veiculadora de pesquisas científicas. Mas, sabemos que há produção científica livremente veiculada 
nela. Porém, se levarmos em consideração inúmeras dificuldades em se chegar aos livros e periódicos científicos impressos, é possível concluir, de modo lógico, que a internet tem sido a ferramenta, pelo menos, mais acessível à comunidade científica.

Uma prova desse aumento da facilidade de acesso a textos científicos pela internet está no movimento conhecido como Acesso Aberto que

[...] pode ser definido como a disposição livre e pública de um texto, de forma a permitir a qualquer um a leitura, cópia, impressão, distribuição e, quando for o caso, download, busca ou o link com o seu conteúdo completo, assim como a indexação ou o uso para qualquer fim não comercial. (ORTELLADO; MACHADO, 2006, p. 9).

Após este movimento surgir e ser defendido em inúmeros documentos tais como "Declaração de Berlim", "Declaração sobre o acesso à informação científica", "Declaração sobre o acesso aos dados de pesquisa com fundos públicos" e "Declaração sobre o acesso aberto à literatura acadêmica e à documentação de pesquisa" e em estudos realizados por pesquisadores como Harnad; Brody; Vallieres; Carr; Hitchcock; Gingras; Oppenheim; Hajjem; Hilf (2004) e Lawrence (2001), tornou-se possível verificar que citações de periódicos de acesso aberto são muito maiores do que as de acesso restrito.

Há ainda de se considerar, entretanto, como já mencionado, que há pouco material online disponível em acesso aberto. Prova disso é, segundo informam Ortellado e Machado (2006), o fato de uma livraria eletrônica científica das mais acessadas como o Scientific Electronic Library Online (Scielo) possuir menos de $10 \%$ das publicações científicas brasileiras. Por que, então, tamanho acesso a um acervo tão restrito?

Tal questão encontra resposta no fato de que editoras de publicações científicas apossam-se de uma enorme quantidade de obras que, mesmo depois de esgotadas, não voltam a circular no mercado científico devido ao impedimento dos direitos autorais e cuja reprodução autônoma é impedida pela Associação Brasileira de Direitos Reprográficos (ABDR).

[...] a ABDR reforça sua representatividade a fim de lutar contra um mal comum aos autores, editores e todos aqueles ligados a essa área: a pirataria de livros.

ABDR incorporou a ABPDEA, e, por decisão de seus associados, cancelou todas as licenças reprográficas. Assim, desde abril de 2004, nenhum centro de cópias está autorizado a reproduzir, parcial ou integralmente, com intuito de lucro, ainda que indireto, qualquer obra de autores e editores associados a ABDR, fora das hipóteses expressamente previstas em Lei. (ABDR, 2008, online) 
Além disso, grandes editoras de periódicos mantêm preços realmente elevados para suas assinaturas. Toda essa dificuldade explica, portanto, a busca crescente da internet e dos artigos de acesso aberto pela comunidade científica.

Aí se esbarra em outra questão. Muitos pesquisadores não consideram como sendo de qualidade o material veiculado em acesso aberto.

[...] a título de exemplo, no Brasil, nas Ciências Sociais, a avaliação oficial de periódicos feita pela Capes atribui aos periódicos exclusivamente digitais a pior classificação ("local C") independente do mérito. Em outras áreas, as publicações digitais simplesmente não são consideradas. (ORTELLADO \& MACHADO, 2006, p. 9).

Essa classificação pode não passar de um preconceito frente à "novidade" do uso da internet como ferramenta científica, mas o que importa é o seguinte: se as pesquisas disponíveis nesse acervo não têm o devido reconhecimento, como fazer com que outras pesquisas com base naquelas tenham garantia de qualidade?

A pressão no meio científico por parte das instituições acadêmicas com a finalidade de quantificar publicações e em relação a questões tais como número de publicações por ano, fator de impacto de periódicos e quantificações de citações acabam gerando, além de atitudes questionáveis como a auto-citação, outras posturas antiéticas.

Instituições acadêmicas precisam medir a produção de seus colaboradores, e isso pode originar práticas não-éticas, dependendo da medida em que é feito. Mensurações quantitativas inspiram os autores a trapacear, enquanto as qualitativas dão amplas oportunidades para que os revisores o façam. Situação equivalente existe em relação ao fator de impacto, essa medida falha e facilmente manipulável de se medir a influência de uma revista científica. A seu favor, é verdade que fornece um estímulo perverso à nãopublicação, enquanto diminui seu denominador (número de itens passíveis de citação) a publicação pode aumentar o impacto percebido para o mesmo numerador (o número de citações). A tentação de manipular fatores de impacto em publicações científicas pode ser interessante para as editoras. Recentemente, a COPE organizou um debate acerca da depravação, ou alteração deliberada de fatores de impacto. Uma forma como isso é feito pelas editoras é pedindo aos autores que insiram referências à sua própria revista como um pré-requisito para a publicação de seus trabalhos. Aqueles em favor desta prática afirmam que a medida de impacto é tão falha que as editoras têm o direito de subvertê-la. (GOOLOGLY \& MOMEN, 2006)

É inegável o acesso a material científico de qualidade disponibilizado de maneira online em fontes como o Portal Periódico (CAPES) cujo uso é, além de gratuito, livre aos usuários das instituições participantes, portal este que

oferece acesso aos textos completos de artigos selecionados de mais de 15.475 revistas internacionais, nacionais e estrangeiras, e 126 bases de dados com resumos de documentos em todas as áreas do conhecimento. Inclui também uma seleção de importantes fontes de informação acadêmica com acesso gratuito na Internet. (Brasil, 2010) 
Porém, será que ampliando gradativamente a publicação de artigos pela rede online também não se facilita que pesquisadores cada vez mais pressionados pela necessidade de volume de publicações acabem recorrendo à internet de modo antiético, plagiando ou semi-plagiando suas informações, buscando atingir uma meta de publicações por ano?

Como resolver, portanto, o impasse da necessidade de conhecimento de fácil acesso à comunidade científica via acesso aberto e o uso que terceiros fazem desse conhecimento? Esbarra-se nesse caso, inegavelmente, em uma questão ética.

É importante destacar que posturas que vão de encontro a ética no meio acadêmico não têm sido meras suposições, mas sim fruto de estudos científicos.

O Wall Street Journal publicou um artigo sobre médicos-escritores que são
pagos pela indústria farmacêutica para elaborar artigos científicos para
publicação com o nome de pesquisadores proeminentes. Essa prática é
denominada ghostwriting e quem a pratica é chamado de ghostwriter
(escritor-fantasma), termos que indicam o anonimato do verdadeiro escritor
nas publicações. Naturalmente, o autor que emprestou seu nome e
credibilidade ao artigo é conivente com a situação, embora quase todos se
defendam afirmando que participaram ativamente da pesquisa.
(BODENHEIMER apud GRIEGER, 2007)

Há ainda de se considerar que nem toda informação advinda da internet é confiável e segura. Como separar, portanto, a informação verdadeira da falsa? Cabe ao pesquisador conhecer o autor do documento fonte de pesquisa que está sendo consultado via web e verificar se este pode ser considerado autoridade no tema. Além disso, deve-se averiguar se a fonte de informação está vinculada a uma instituição que se responsabiliza pela confiabilidade cientifica dos dados divulgados via web. O pesquisador deve verificar se os artigos pesquisados estão em revistas indexadas e também é preciso verificar se as informações ali transmitidas não são desmentidas em outros textos disponíveis eletronicamente.

Nos centros acadêmicos, é preciso repensar a necessidade de um espaço para reflexão ética sobre o que é e para que serve a ciência. A ciência não é um conjunto de idéias imutáveis e irrefutáveis visto que é construída por homens dotados de subjetividades e intenções próprias. A ciência é advinda de um conhecimento racional que poderá sempre ser corrigido, adaptado, questionado. É uma tentativa de explicação e reconstrução da realidade. Todavia, a ciência feita com ética é aquela que deve procurar, ao seu máximo, por criações e reflexões que levem a sociedade a um bem maior. De modo mais palpável, fazer ciência com ética é se valer da energia nuclear de forma controlada para obter movimento, para gerar 
eletricidade, enquanto fazer uma ciência sem ética é se valer da mesma energia para produzir bombas atômicas e dizimar nações.

É preciso, portanto, pensar juntamente com os alunos vinculados aos centros de pesquisa qual a finalidade de se produzir ciência e a necessidade de se construir um saber ético. A produção de um texto simplesmente para engrossar currículos certamente não terá a preocupação fundamental de construir saber científico, mas atender às exigências acadêmicas e burocráticas.

Obviamente que é necessária a publicação de textos como resultado de pesquisa financiada por instituições fomentadoras. É uma maneira de justificar o investimento feito e demonstrar ao órgão financiador e à comunidade acadêmica o retorno como resultado do exercício de investigação. A viabilização de publicações apenas para atingir quantidade faz muitos pesquisadores assumirem uma postura antiética. $\mathrm{Na}$ internet, ocorrem vendas de produções científicas, as quais ocorrem de maneira simplificada e de fácil acesso.

Tais práticas - controversas quanto à sua ilegalidade ou não no âmbito criminal, uma vez que considerada por alguns especialistas da área de Direito como estelionato, falsidade ideológica ${ }^{3}$ e, por outros, como prática não ilegal devido à cessão da autoria - são, sem dúvidas, um acentuado dilema moral e ético.

A prática de venda de trabalhos científicos usando a internet como canal é outra questão para a qual não se pode fechar os olhos. Na edição de número 205, a revista Época, através de texto de Nelito Fernandes, trouxe uma relação de endereços virtuais em que se encontram ofertas de trabalhos por encomenda. É o que mostra o quadro 1.

\footnotetext{
3 "O que talvez estudantes incautos não saibam é que estão praticando o famoso 171 , crime de estelionato, além de, eventualmente, outros dois: falsidade ideológica (artigo 229) e violação de direito autoral (artigo 184)". (RODRIGUES, 2002).
} 
Quadro 1 - Endereços virtuais que oferecem a venda de trabalhos acadêmicos.

\begin{tabular}{|c|c|}
\hline \multicolumn{2}{|c|}{$\begin{array}{l}\text { AJUDA.COM.BR } \\
\text { Há vários endereços que oferecem trabalhos para consulta }\end{array}$} \\
\hline $\begin{array}{l}\text { Zé Moleza } \\
\text { www.zemoleza.com.br }\end{array}$ & $\begin{array}{l}\text { Trabalhos de ensino médio e universitários. } \\
\text { Espécie de ponto de intercâmbio de trabalhos } \\
\text { prontos. É gratuito }\end{array}$ \\
\hline $\begin{array}{l}\text { Trabalhos Prontos } \\
\text { www.trabalhosprontos.com.br }\end{array}$ & $\begin{array}{l}\text { Faz trabalhos personalizados sob encomenda. } \\
\text { Especializado em ciências humanas e exatas. } \\
\text { Cobra até } R \$ 3 \text { por página }\end{array}$ \\
\hline $\begin{array}{l}\text { Mina de Idéias } \\
\text { www.minadeideias.hpg.com.br }\end{array}$ & $\begin{array}{l}\text { Aceita encomendas de trabalhos simples ( } \mathrm{R} \$ \\
80 \text {, com } 12 \text { páginas) até dissertações de } \\
\text { mestrado (em } 12 \text { dias, } R \$ 2.500 \text { ) }\end{array}$ \\
\hline $\begin{array}{l}\text { Via Busca } \\
\text { www.viabusca.com/trabalhos.html }\end{array}$ & $\begin{array}{l}\text { Não é um site de trabalhos prontos, mas tem } \\
\text { links para } 102 \text { deles }\end{array}$ \\
\hline $\begin{array}{l}\text { School Sucks } \\
\text { www.schoolsucks.com }\end{array}$ & $\begin{array}{l}\text { O original, americano, com } 10 \text { mil visitantes por } \\
\text { dia, vende trabalhos prontos por US } \$ 5 \text { a } \\
\text { página }\end{array}$ \\
\hline $\begin{array}{l}\text { Portal dos Estudantes } \\
\text { www.portaldosestudantes.cjb.net }\end{array}$ & $\begin{array}{l}\text { Reúne informações para estudantes e } \\
\text { trabalhos prontos de } 31 \text { áreas. É gratuito }\end{array}$ \\
\hline $\begin{array}{l}\text { Repositório de Monografias e Trabalhos } \\
\text { www.geocities.com/trabalhos_prontos/ }\end{array}$ & $\begin{array}{l}\text { Trabalhos para download divididos em oito } \\
\text { especialidades. Tem poucas pesquisas. É } \\
\text { gratuito }\end{array}$ \\
\hline $\begin{array}{l}\text { Mundo Acadêmico } \\
\text { www.mundoacademico.rg3.net/ }\end{array}$ & $\begin{array}{l}\text { Com trabalhos prontos em } 19 \text { áreas, é um dos } \\
\text { mais antigos da rede. Preços a partir de } R \$ 10\end{array}$ \\
\hline
\end{tabular}

Fonte: Fernandes, 2002.

Fica clara, portanto, outra urgência no meio científico: a de se encontrar, no ambiente científico, o "meio-termo" aristotélico. Assim, a finalidade da publicação deve ser primeiramente a de engrossar o conhecimento da comunidade científica e da sociedade que usufrui desse conhecimento. $O$ alargamento do currículo acadêmico virá como consequência, e não como causa do trabalho de produção científica. Como já pregou Aristóteles, "a virtude moral é adquirida em resultado do hábito". Assim, pesquisando, escrevendo e, acima de tudo, refletindo com as leituras realizadas e com o conhecimento produzido é que o homem pesquisador merecerá 0 atributo de cientista.

Portanto, levando em conta os aspectos éticos no uso da internet como instrumento de pesquisa científica, podemos produzir conhecimentos mais verdadeiros. Não obstante a isso, temos o compromisso de analisar, do ponto de vista ético, não somente os textos disponíveis na web, mas, sobretudo demonstrar 
os equívocos científicos disponíveis nesse meio de divulgação. Esses são os principais cuidados a serem observados pelos pesquisadores que fazem uso da internet na produção de seus textos e, nos resultados das suas pesquisas científicas. Assim, então, podemos afirmar que a internet é um meio importante e que pode contribuir com a ciência, desde que as informações disponíveis aí sejam avaliadas sob o olhar crítico e, principalmente, ético. Pesquisar com ética significa verificar os ganhos e os benefícios que o ser humano terá com o resultado da pesquisa científica.

\section{REFERÊNCIAS}

ARISTOTELES. Ética a Nicômaco. São Paulo: Martin Claret, 2003.

BRASIL. Portal periódicos CAPES.(On line). Disponível em: http://www.periodicos.capes.gov.br/portugues/index.jsp. Acesso em: 10 jan. 2010.

DALBERIO, O. Perspectivas éticas para a educação. EDUCERE (MéridaVenezuela), v. 1, p. 241-245, 2007.

. Ética na pesquisa científica. Revista da Sociedade de Psicologia do Triângulo Mineiro, Uberlândia - MG, v. 11, p. 36-49, 2007.

Os desafios éticos da pesquisa social. Tese (Doutorado em Serviço Social) Faculdade de História, Direito e Serviço Social da Universidade Estadual Paulista - UNESP, 280p. 2008.

JOSÉ FILHO, Mário. Ética e pesquisa na produção do conhecimento. Información Filosofica . Roma- Itália, v. VI, p. 07-26, 2009.

DINIZ, Débora. A ética e o ethos da comunicação científica. Série Anis, n. 55, Brasíliam LetrasLivres, 1-3, junho, 2008. Disponível em: < http://www.anis.org.br/serie/artigos/sa55_diniz_comunicacaocientifica.pdf>. Acesso em 03.Jan.2009.

DUPAS, G. Ética e poder na sociedade da informação. 2.ed. São Paulo: Editora UNESP, 2001.

FERNANDES N. Cola on-line. Revista Época. 2002 Abr 22; 205.ed. Disponível em <http://epoca.globo.com/edic/205/socia.htm> Acesso em 16.Jan.2010.

GRIEGER, Maria Christina Anna. Escritores-fantasma e comércio de trabalhos científicos na internet: a ciência em risco. Rev. Assoc. Med. Bras., São Paulo, v. 53, n. 3, jun. 2007 . Disponível em <http://www.scielo.br/scielo.php?script= sci_arttext\&pid=S0104-42302007000300023\&Ing=pt\&nrm=iso>. Acesso em 01 jan. 2010. 
GOLLOGLY, Laragh; MOMEN, Hooman. Ethical dilemmas in scientific publication: pitfalls and solutions for editors. Rev. Saúde Pública, São Paulo, v. 40, n. $\quad$ spe, ago. 2006. 2 Disponível em $<$ http://www.scielo.br/scielo.php?script=sci_arttext\&pid=S0034-

$89102006000400004 \&$ Ing=pt\&nrm=iso >. Acesso em 01 jan. 2010.

HARNAD, S., Brody, T., Vallieres, F., Carr, L., Hitchcock, S., Gingras, Y, Oppenheim, C., Hajjem, C., \& Hilf, E. (2004) The Access/Impact Problem and the Green and Gold Roads to Open Access: An Update. Serials Review 34: 36-40. Disponível em: <http://eprints.ecs.soton.ac.uk/15852/2/serev-revised.pdf> Acessado em 20/01/2009.

LAWRENCE, S. Free Online Availability Substantially Increases a Paper's Impact. Nature vol. 411, n. 6837, 31 de maio de 2001. Disponível em: <http://www.nature.com/nature/debates/e-access/Articles/lawrence.html> Acesso em 20.Jan.2009.

MARCONDES, D. Textos básicos de ética de Platão a Foucault. Rio de Janeiro: Zahar, 2007.

MARTINI, C. M. Viagem pelo vocabulário da ética. Tradução de Mário Santos. São Paulo: Paulus, 1994.

ORTELLADO, Pablo \& MACHADO, Jorge Alberto. Direitos autorais e o acesso às publicações científicas. Revista Adusp, São Paulo, agosto, 2006. Disponível em <http://www.abdr.org.br>. Acesso em 05.Nov.2008.

RIOS, Terezinha Azeredo. O que será da avaliação sem a ética? GUARÁ, Isa Maria F. Rosa. Cadernos CENPEC - Avaliação em educação. São Paulo: CENPEC, n. 3, jan.-março, p.45-52. 2007.

RODRIGUES G \& MORAES R. PhD de aluguel. Revista IstoÉ. 2002 Abr 19; 1699. ed. Disponível em

http://www.istoe.com.br/reportagens/21750_PHD+DE+ALUGUEL?

pathImagens $=\&$ path $=\&$ actualArea=internalPage $>$ Acesso em 16.Jan.2010.

TUGENDHAT, Ernst. Lições Sobre Ética. Petrópolis: Vozes. 2003.

VÁZQUEZ, A. S. Ética. tradução de João Dell’Anna. 28. ed. Rio de Janeiro: 2006.

ZAJDSZNAJDER, L. Ética, estratégia e comunicação: na passagem da modernidade à pós-modernidade. 2. ed. Rio de Janeiro: Editora FGV, 2002.

Recebido para publicação em: 25/01/09

Aceito: 30/07/09 